\title{
Sensory representation within the cerebellum of the pigeon
}

The sensory representation within the cerebellum of pigeons, cats, and monkeys has been studied by several investigators ${ }^{1-9}$. These investigators, with the exception of Woolsey et al., have used large electrodes and have recorded chiefly from the surface of the cerebellum. The purpose of the present study was to obtain more information by using microelectrodes to study the response of single cells to stimulation of the auditory, visual, proprioceptive and tactual systems. The pigeon was of interest because it lacks of a well developed cerebral cortex but has a proportionately large, but comparatively simple cerebellum as compared to mammals. Evidence will be presented which will demonstrate that the cerebellum has the same detailed functional representation as is found for the sensory area of the cerebral cortex of many of the higher mammals.

The data to be presented were obtained from white Carneaux pigeons which were etherized and destriated. Ketamine (Park Davis and Co.) was injected to quiet the animal during testing. The animal was secured in a tripodal head holder and the bone over the cerebellum was removed. Small cuts were made in the dura to permit entry of the recording microelectrodes. The responses were fed to a high impedance unity gain amplifier and displayed on an oscilloscope after appropriate amplification. The brains were sectioned sagittally and the responses were located along the tracks.

Slow wave responses and single unit responses to clicks and pure tones between 0.08 and $1.4 \mathrm{kc} / \mathrm{sec}$ were recorded. Between these limits the stimulus range which would evoke a response differed for different locations, but the data were too few to determine whether there was a tonotopic organization. The responses consisted typically of an 'on' response of 1-3 spike potentials and this rate of discharge did not change with increased intensity or length of the pure tones.

The location of the auditory responses is summarized in Table I. Table I includes the data obtained from all the electrode penetrations. Under the Sense modality and Folium designations the figures indicate the total number of penetrations from which information was recorded, from a particular folium, for a given sense modality and part of the body. Many of the penetrations yielded one or more units for a particular sense modality. For example, there were 16 penetrations which yielded proprioceptive responses from the cervical vertebrae. Sixty-two units were recorded within these 16 penetrations. The column labeled No. units, number of units, includes the total number of units recorded from stimulation of a sensory system and particular part of the body. More than one sense modality and part of the body could be represented in one folium. Included within this number are units which were identified as to sense modality but the histology was not available so that the location of the units in a particular folium could not be designated. The column labeled Total is the number of units recorded for each of the sense modalities and for the major divisions of the body.

Auditory responses were distributed from folium F II through VIII, with the greatest concentration within F VI through VIII. In all cases the responses were found in the lower half of the folia and within the lateralmost aspect of the folia.

Brain Research, 21 (1970) 280-283 
TABLE I

LOCI FOR SENSORY RESPONSES IN THE FOLIA OF THE PIGEON CEREBELLUM

\begin{tabular}{|c|c|c|c|c|c|c|c|c|c|c|c|c|}
\hline \multirow[t]{2}{*}{ Sense modality } & \multicolumn{10}{|c|}{ Folium } & \multirow{2}{*}{$\begin{array}{l}\text { No. } \\
\text { linits }\end{array}$} & \multirow[t]{2}{*}{ Total } \\
\hline & $I$ & II & 111 & $I V$ & $V$ & $V I$ & $V I I$ & VIII & $I X$ & $X$ & & \\
\hline \multicolumn{13}{|l|}{ Audition } \\
\hline Slow wave responses & & 3 & 2 & 3 & 2 & 9 & 4 & & & & & \\
\hline Unit responses & & & & 1 & & 1 & 10 & 5 & & & & 17 \\
\hline \multicolumn{13}{|l|}{ Vision } \\
\hline Slow wave responses & & & & 1 & 2 & 3 & 1 & 1 & 1 & & & \\
\hline Unit responses & & & & 1 & 3 & 9 & 6 & 1 & 1 & & & 21 \\
\hline \multicolumn{13}{|l|}{$\begin{array}{l}\text { Proprioception } \\
\quad \text { (unit responses) }\end{array}$} \\
\hline Beak & & & & & & 1 & & & & & 2 & \\
\hline Cervical vertebrae & & & & 4 & 4 & 6 & 2 & & & & 62 & \\
\hline Wing joints & & & & 4 & 5 & 7 & 3 & & & & 43 & \\
\hline Leg & & & & 1 & 1 & 1 & & & & & 3 & 110 \\
\hline \multicolumn{13}{|l|}{$\begin{array}{l}\text { Touch } \\
\text { (unit responses) }\end{array}$} \\
\hline \multicolumn{13}{|l|}{ Head } \\
\hline Crown & & & & & 2 & 11 & 6 & 2 & & & 61 & \\
\hline Nostril cere & & & & & 1 & 11 & 5 & 1 & & & 58 & \\
\hline Beak & & & & & & 1 & 2 & & & & 17 & \\
\hline Eye lid & & & & & & 1 & & & & & 10 & \\
\hline Cornea & & & & & & 1 & 1 & & & & 5 & 151 \\
\hline
\end{tabular}

Throat

$\begin{array}{lrrrrrrrr}\text { Upper } & & 2 & 13 & 4 & & 24 & \\ \text { Lower } & 1 & 2 & 14 & 5 & 1 & 25 & \\ \text { Lateral } & & & 1 & 1 & 1 & 8 & 57\end{array}$

Breast

$\begin{array}{lrrrrr}\text { Anterior } & 4 & 1 & 1 & 22 & \\ \text { Posterior } & 2 & & & 9 & 31\end{array}$

Leg

Leg $\quad 3 \quad 3$

\begin{tabular}{lll} 
Tarsus & 3 & 3 \\
\hline
\end{tabular}

Toes

$12 \quad 5 \quad 1 \quad 18$

$\begin{array}{llllr}\text { Back } & 1 & 5 & 1 & 18 \\ \text { Tail } & & 5 & 2 & 13\end{array}$

Nape $\quad 5$

Wing

$\begin{array}{llll}\text { Coverts and wing bars } & 11 & 6 & 42\end{array}$

Coverts under wing

Wing flights

$\begin{array}{rrrrr}1 & 2 & 5 & 13 & 7\end{array}$

77 
Slow wave and single unit responses were recorded to white light stimulation. Responses to light stimulation were 'on'-'off' discharges and were recorded from F IV through IX, with the greatest concentration of responses being found in F VI and VII (see Table I). The responses were localized in the lateralmost aspects of these folia.

The data obtained from single unit proprioceptive responses are presented in Table 1. The largest number of units responded to movement of the cervical vertebrae, followed by wing joints, etc. In some cases there was no spontaneous discharge of the unit and movement caused the unit to discharge; in other cases the units were discharging rhythmically and stimulation caused an increased rate of discharge; and finally in some cases the units were discharging spontaneously and movement inhibited the discharge. Responses were usually related to specific movements, forward or backward movement of the neck, abduction or adduction, flexion or extension of the wings and legs. The proprioceptive responses were found uniformly distributed from F IV through F VII. In most cases the units were located within the intermediate and lateral aspects of the folia. There was no evidence of an organized projection of the proprioceptive system within the cerebellum.

Single unit responses to touch stimulation were recorded from movement of the feathers or deformation of the skin surface or brushing the surface of the cornea (see Table I). The largest number of units was found when the head was stimulated, followed by the wing, etc. In most cases the units did not discharge spontaneously and stimulation, with the exception of the cornea, gave rise to an 'on'.. 'off' response for each stimulation, with no afterdischarge. The loci for the single unit responses for touch for the body were spread from F II to VIII with the greatest concentration of units within the 3 subfolia of F VI and VII. An analysis of the data leads to the following tentative conclusions. Responses from the head, throat, and body are found principally in F VIa, responses from the leg, tail, and wing are found principally in F VIb. Responses from the head, throat, etc. are again represented for a second time in VIc and VII. Additional data would be required to define the medial to lateral distribution for the broader areas of response for example, the head versus the wing areas. The data suggest that in the pigeon there is as detailed a somatotopic representation of the body in the cerebellum as one finds in the cerebral cortex of higher mammals.

The conclusions of the present study differ from those obtained by Whitlock ${ }^{9}$ on the pigeon. These differences can be ascribed principally to differences in size of the recording electrodes and a more detailed analysis of individual folia in the present study.

The investigation was supported by Grant NB-05102 from the National Institutes of Health, Office of Naval Research, Contract No. NR-4422, and the Program Project Grant NS-05785.

The author wishes to express his indebtedness to Mr. Franz Weiser for the design and construction of mechanical systems; to Mrs. Janice Myerson who assisted in the experiments; to Mrs. Judith Miller for preparing the anatomical material, and 
to Mrs. June G. Ludwig for typing the manuscript. The advice given by Dr. Max Bree, D.V.M. of the Animal Care Unit on problems of anesthesia is greatly appreciated.

Department of Otorhinolaryngology,

NATHAN B. GROSS

Kresge Hearing Research Institute,

University of Michigan Medical School,

Ann Arbor, Mich. 48104 (U.S.A.)

1 AdRiAn, E. D., Afferent areas in the cerebellum connected with the limbs, Brain, 66 (1943) 289-315.

2 Dow, R. S., The fiber connections of the posterior parts of the cerebellum in the rat and cat, J. comp. Neurol., 63 (1936) 527-548.

3 Dow, R. S., Cerebellar action potentials in response to stimulation of various afferent connections, J. Neurophysiol., 2 (1939) 543-555.

4 Dow, R. S., AND ANDERSon, R., Cerebellar action potentials in response to stimulation of proprioceptors and exteroceptors in the rat, J. Neurophysiol., 5 (1942) 363-371.

5 Grundfest, H., ANd Campbell, B., Origin, conduction and termination of impulses in the dorsal spinocerebellar tracts of cat, $J$. Neurophysiol., 5 (1942) 275-294.

6 Koella, W. P., Functional properties of optically evoked potentials in the cerebellum of the cat, Fed. Proc., 17 (1958) 89.

7 SNider, R. S., AND Stowell, A., Receiving areas of the tactile auditory and visual systems in the cerebellum, J. Neurophysiol., 7 (1944) 331-358.

8 WoOlsey, C. N., Adrian, H., AND Lifschitz, W., Activity of neural units in the auditory area of the cerebellum of decerebrate cats, Science, 146 (1964) 435.

9 Wнітьоск, D. G., A neurohistological and neurophysiological study of afferent fiber tracts and receptive areas of the avian cerebellum, J. comp. Neurol., 97 (1952) 567-623.

(Accepted May 13th, 1970) 